\title{
Las nuevas fronteras de la comunicación corporativa
}

\author{
Miriam Rodríguez-Pallares \\ Universidad Complutense de Madrid
}

\section{Referencia de este artículo}

Rodríguez-Pallares, Miriam (2020). Reseña de Las nuevas fronteras de la comunicación corporativa. En adComunica. Revista Científica del Estrategias, Tendencias e Innovación en Comunicación, $\mathrm{n}^{\circ}$ 20, Castellón: Universitat Jaume I, 389-390. DOI: http://dx.doi.org/10.6035/2174-0992.2020.20.18.

Las nuevas fronteras de la comunicación corporativa

García Santamaría, José Vicente (2019).

Barcelona: UOC.

Las relaciones entre las empresas y sus públicos viven un constante período de adaptación. En un escenario marcado por la globalización económica, política y tecnológica, radiografiar el papel y la evolución de la comunicación corporativa se plantea imprescindible e inevitable para dotar a la profesión y, en especial, a su enseñanza del valor que le es justo.

Confiesa el autor que Las nuevas fronteras de la comunicación corporativa no se plantea como un texto académico, ni como una recopilación de experiencias; tampoco como un manual, sino como «una reflexión sobre el devenir de la comunicación corporativa desde los años ochenta hasta hoy día» (p. 18). Y, sin embargo, es un compendio de todo ello. García Santamaría, profesor titular del Departamento de Comunicación de la Universidad Carlos III de Madrid, logra aunar en este libro un profuso conocimiento del sector -amparado por más de veinte años de expe- 
riencia al servicio de la comunicación corporativa en diferentes entidades- con la rigurosidad y sistematicidad propias de la investigación académica.

Analizar el presente y abordar prospectivas futuras no es recomendable sin el estudio del pasado. Esta premisa podría justificar la lógica de este libro, que se estructura en dos grandes bloques: «La persistencia de los elementos clásicos», donde se describen los aspectos identitarios de la comunicación corporativa ayer y hoy, y «Las nuevas fronteras», espacio en el que se abordan las nuevas competencias y funciones que, enmarcadas bajo el paraguas de la digitalización, responden a las exigencias de las corporaciones en su carrera por empatizar y alcanzar la confianza de sus stakeholders.

Los capítulos que conforman el esqueleto de la narración dan buena fe de labor investigadora y la capacidad de jerarquización y síntesis del autor que, con un estilo ágil y cargado de ejemplos, logra simplificar lo complejo y profundizar en aspectos imprescindibles para entender el actual ecosistema comunicativo y las competencias profesionales atribuidas al responsable de la comunicación corporativa. En este sentido, se adelanta, en el capítulo I, lo que bien puede ser una conclusión final: «los expertos deberán de ser capaces de desempeñar su tarea en diferentes medios, lenguajes y formatos, impulsar e interpretar cualquier tipo de investigación cuantitativa y cualitativa, poseer los necesarios conocimientos de economía, saber mucho más de procesos de transparencia y buen gobierno moverse con mayor soltura en el ámbito digital, incorporar el big data, la inteligencia artificial (IA) y la robótica a sus nuevos conocimientos, integrar en su visión la responsabilidad corporativa y las estrategias medioambientales o disponer de la capacidad de trazar e implementar sofisticadas estrategias de comunicación» (p. 27-28).

Se trata, en definitiva, de una publicación altamente recomendable para comprender una actividad profesional a caballo entre diferentes disciplinas y cuya proyección social y económica es hoy incuestionable. Y, aunque la obra se reconoce pensada para «contribuir a la formación de las nuevas hornadas de alumnos de grado y postgrado» (p. 20), las bondades de su lectura trascienden las barreras universitarias y, con seguridad, resultarán de interés para todo aquel interesado en establecer contacto con el amplio y complejo mundo de la comunicación corporativa. 